\title{
Beating heart disease
}

\section{A Change of Heart: How the People of Framingham, Massachusetts, Helped Unravel the Mysteries of Cardiovascular Disease \\ by Daniel Levy \& Susan Brink \\ Alfred Knopf: 2005. 247 pp. \$26.95}

\section{Peter Sleight}

The Framingham Heart Study began in 1948 and has run for nearly 60 years. By documenting the health and lifestyles of a small New England community, it identified many of the risk factors, such as blood pressure, cholesterol and smoking that are now associated with heart disease and stroke. In Change of Heart, Daniel Levy, the current director of the Framingham study, and journalist Susan Brink tell the history of this epidemiological research. The combination of history, anecdotes and the political intrigue necessary for the Framingham study to survive should interest professionals as well as the lay public at which this book is aimed.

This book holds many lessons for the present, as we're now seeing huge increases in funding for basic research - but at the expense of clinical and epidemiological studies. Distinguished scientists predict a future in which basic research will be rapidly translated into therapeutic trials, and then to clinical practice, as exemplified by the statins. These academics now dominate the committees that distribute research money, and they naturally favour basic research. They give scant credit to those who identified their laboratory targets - clinicians and epidemiologists such as Ancel Keys, whose 'seven countries' study linked cardiovascular disease to the consumption of saturated fats. Huge amounts of money are spent on genomic research.

Levy and Brink speculate that known risk factors explain only half the causes of heart attack, and that genomic research might identify new targets. But the recent INTERHEART case-control study of heart attack in 52 countries, run on a shoestring budget by Salim Yusuf of McMaster University in Canada and colleagues, shows that $90 \%$ were predicted by known risk factors, many of them documented in the Framingham database.

Change of Heart sympathetically describes the naive enthusiasm and ideals of the early Framingham pioneers. Roy Dawber and Bill Kannel thought that giving 5,000 middle-aged people from a 'typical' US community 20 annual medical examinations would reveal the causes of the increasing scourge of heart attacks. They later took advantage of emerging technology, such as electrocardiograms and ultrasound, to add to their clinical and blood data. They also soon realized that they needed a crash course in data handling and epidemiological methods. In the early years, the data

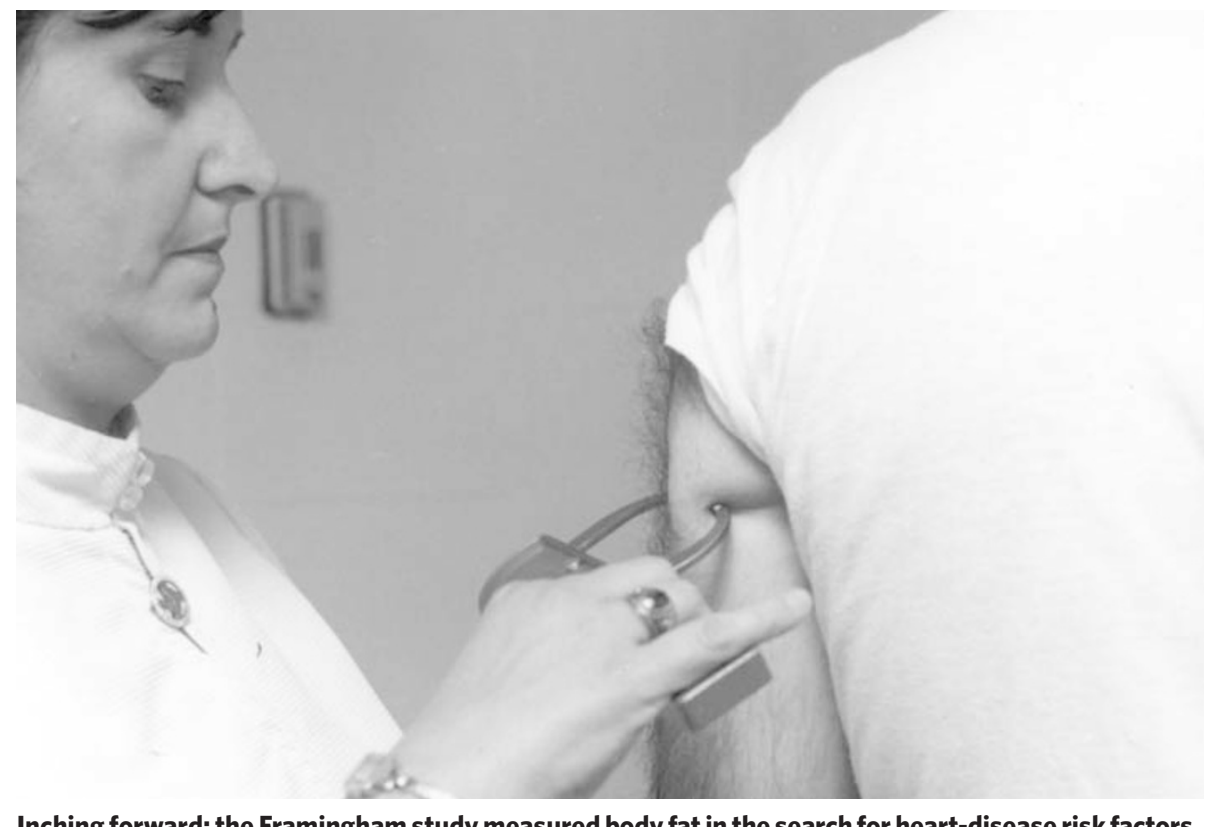

Inching forward: the Framingham study measured body fat in the search for heart-disease risk factors.

were all on paper and were legally controlled by the National Heart, Lung and Blood Institute (NHLBI), which did not always cooperate by releasing it to the Framingham staff. Fortunately, Dawber and Patricia McNamara kept duplicate copies. The project then used IBM punch cards, and finally modern information technology.

Another lesson for our times was the somewhat arbitrary administrative decision by the NHLBI to axe the study in 1968 , just at the time when the endpoints - deaths, heart attacks and strokes among those enrolled in the study - were beginning to increase. The study was saved by the subsequent outcry from both subjects and researchers, including cardiologist Paul Dudley White, who wrote to President Nixon.

The four directors of Framingham, Dawber, Kannel, William Castelli and Levy, have preserved the original ethos of putting the subjects first. The subjects developed their own representative board and, more important, gave their time and data for the benefit of medical research. They managed to derail a plan by Framingham Genomic Medicine, a collaboration between Boston University and a group of rich venture-capitalists, to market the data and DNA samples to interested researchers and drug companies. But the collaboration was faced with the threat of the withdrawal of many participants, who first read of the planned deal in the newspapers, with no prior consultation with either project staff or subjects. Boston University finally withdrew from the project. Framingham survived the crisis, and the subjects agreed that their anonymized data and DNA should be a freely available database for scientific research.
Inevitably, there are some weaknesses in the Framingham study. Key among these is the relatively small number of subjects - commentators have remarked that there seem to be more publications on Framingham than there are subjects in the study! Another problem is that the data from this New England community are not universally applicable to other areas or countries. Country- and communityspecific risk data have now been obtained elsewhere, by the European SCORE project, for example.

On the other hand, the strengths of the study are immense. No other study has data from three generations of subjects, for instance. The choice of the community of Framingham (near Boston) was fortunate, too - unlike other possible choices in 1948, it had the support of a local university, which proved crucial in the 1968 closure crisis. And it has been very well managed, has fostered great loyalty, and few subjects have been lost from follow-up studies.

The Framingham study had some spectacular successes, notably the continuous relationships between blood pressure, cholesterol, cigarette consumption and long-term risk. This led to landmark hypertension trials carried out by Ed Freis, which were delayed for years by dogmatic assertions that treatment would be dangerous or that a trial would be unethical.

All in all, A Change of Heart is an easy but exciting read. We owe a lot to Framingham, and the staff and subjects deserve our gratitude. The book will be a bestseller in Boston and deserves to be so elsewhere.

Peter Sleight is in the Department of Cardiovascular Medicine, University of Oxford, Oxford OX3 9DU, UK. 